\title{
Muscle biopsy findings, conduction velocity and refractory period of single motor nerve fibres in schizophrenia
}

\author{
J BORG,${ }^{*} \dagger$ L EDSTRÖM,† L BJERKENSTEDT, $\ddagger$ F-A WIESEL,$\S$ L FARDE, \\ LHAGENFELDT\|
}

From the Karolinska Institute Departments of Neurology, Söder Hospital* and Karolinska Hospital, $\dagger$ Department of Psychiatry, Danderyd Hospital, $\ddagger$ Department of Psychiatry and Psychology, Karolinska Hospital,§ and Department of Clinical Chemistry, Karolinska Hospital, $\|$ Stockholm, Sweden

SUMMARY Eight untreated and eight neuroleptic treated male schizophrenic patients were studied. Light and electron microscopical analysis of muscle biopsies from the anterior tibial muscle showed a spectrum of pathological changes without significant quantitative or qualitative differences between the two groups. The changes included atrophic fibres, central nuclei, "moth-eaten fibres", "ring fibres", fibre splitting and subsarcolemmal and intermyofibrillar glycogen droplets. Electrophysiological investigation of single motor unit properties showed impaired peripheral impulse propagation in both patient groups while the conduction velocity and the refractory period of single motor nerve fibres were within the same range as in healthy subjects. In conclusion there are neuromuscular abnormalities in schizophrenic patients which cannot be attributed to medication or drug abuse.

Different signs of neuromuscular dysfunction have been described in patients suffering from schizophrenia. Clinically there are, however, very little clear-cut observations pointing to a disturbance primarily affecting the peripheral motor system. A reduced muscular tone has been reported in some children suspected to be suffering from a psychosis. ${ }^{12}$ In the children described by Cantor $e t \mathrm{al}^{2}$ the reduced muscular tone was often combined with hyporeflexia and increased joint mobility. Slight aberration in muscle fibre diameter was reported in muscle biopsies from some of these cases. In some unaffected children of schizophrenic mothers abnormalities of muscular tone and motor development have been reported. ${ }^{34}$

Laboratory findings raising the question of a peripheral neuromuscular dysfunction have been reported in a large number of papers: serum creatine kinase (CK) activity was found to be elevated in psychotic patients especially during acute phases. ${ }^{5-7}$ Increased branching of subterminal motor nerves has been described ${ }^{8}$ as well as increased motor unit fibre

Address for reprint requests: J Borg, Department of Neurology, Söder Hospital, S-100 64 Stockholm, Sweden.

Received 17 March 1987. Accepted 22 May 1987 density. ${ }^{9}$ Morphological changes of different kinds were described in muscle biopsy material from psychotic patients. ${ }^{6}$ It is, however, uncertain whether drug addiction, medication or some procedures related to the treatment might play a part in the occurrence of signs of peripheral neuromuscular dysfunction.

In the present project we aimed at a parallel study of two groups of schizophrenic patients, one during medical treatment and one drug free, for comparison with healthy subjects. The analysis of neuromuscular function included muscle biopsy from a carefully standardised site of the anterior tibial muscle and a concomitant neurophysiological analysis of motorneuronal properties in foot extensor motor units.

\section{Material and methods}

\section{Patients}

Two groups of male schizophrenic patients were investigated: eight with and eight without ongoing drug therapy. The diagnosis of schizophrenia was made according to $\mathrm{RDC}^{10}$ and DSM III. Data regarding age, duration of illness and reported drug intake are presented in tables 1 and 2 . Nine male healthy volunteers in the same age range were investigated as well. They had never been psychiatrically ill and had no first degree relatives with psychiatric illness. 
Table 1 Clinical description of male drugfree schizophrenic patients

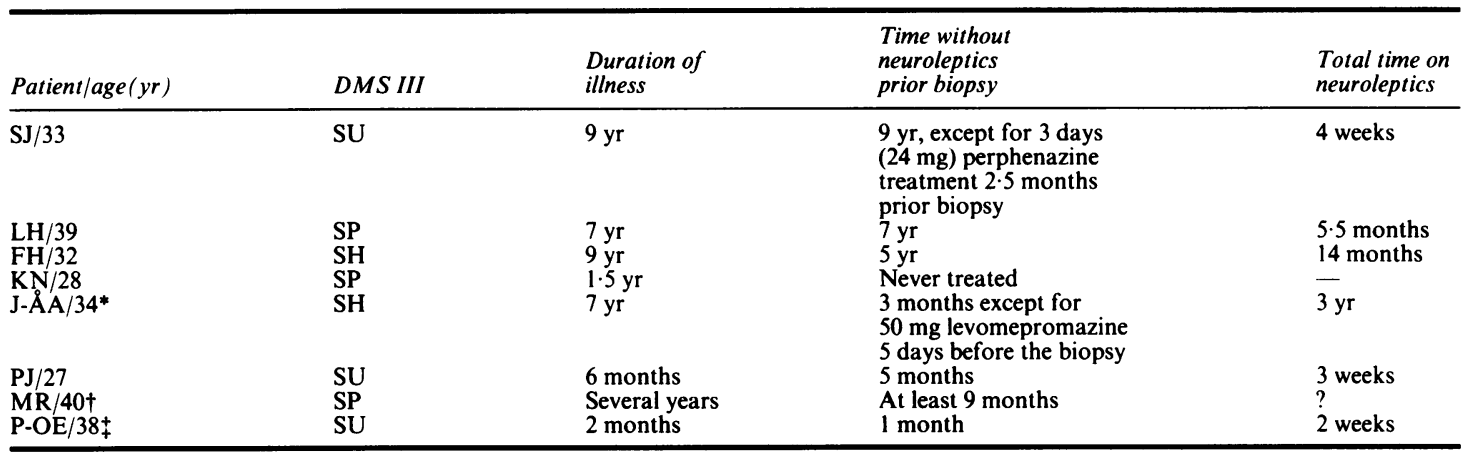

*Several years of regular consumption of diazepam $15-30 \mathrm{mg} /$ day in the early phase of disease.

†From Iraq, moved to Sweden 16 months before entering the study.

$\ddagger$ Duration of illness including the time after biopsy more than 6 months, 1 year before biopsy periodical abuse of alcohol.

Schizophrenia (S): $\mathbf{H}=$ hebephrenia, $\mathbf{P}=$ paranoid, $\mathrm{U}=$ undifferentiated.

Neither the patients nor the volunteers had any known neuromuscular disorder. Subjects with substance abuse, neurological disturbances or head trauma were excluded. All the subjects were in good general health.

\section{Muscle biopsy procedure}

Muscle biopsy was made in the anterior tibial muscle (TA) by the percutaneous method of Radner as described by Lindholm. ${ }^{11}$ At least two pieces of muscle were obtained: one was immediately freshly frozen in liquid Freon 13, kept at its melting point by liquid nitrogen and the other pinned under slight tension with insect needles on a piece of cork and fixed in $2.5 \%$ glutharaldehyde in phosphate buffer $(\mathrm{pH}$ $7 \cdot 2$ ) and postfixed in $2 \%$ osmium tetroxide. The freshly frozen material was then kept in a refrigerator at $-80^{\circ} \mathrm{C}$ and later sectioned in a cryostat at $-30^{\circ} \mathrm{C}$.

The cryostat sections (12-16 $\mu \mathrm{m}$ thick) were stained with haematoxylin-eosin trichrome, ${ }^{12}$ and for myosin ATPase activity at $\mathrm{pH} 9 \cdot 4^{13}$ with and without acid preincubations, ${ }^{14} \mathrm{D}$ NADH-TR, menadione-linked alfa-glycerophosphate dehy-官

Table 2 Clinical description of male schizophrenic patients on neuroleptic treatment

\begin{tabular}{|c|c|c|c|c|}
\hline Patient/age (yr) & $D M S I I I$ & $\begin{array}{l}\text { Duration of } \\
\text { illness }\end{array}$ & $\begin{array}{l}\text { Actual } \\
\text { drug treatment }\end{array}$ & $\begin{array}{l}\text { Total time } \\
\text { on neuroleptic } \begin{array}{l}\text { (yr) } \\
(y)\end{array}\end{array}$ \\
\hline $\mathrm{HM} / 24^{*}$ & SH & $3 \cdot 3$ & $\begin{array}{l}\text { Cix(Z)-clopenthixol } \\
\text { decanoate } 300 \mathrm{mg} / \text { week } \\
\text { oxazepam } 45 \mathrm{mg} / \text { day } \\
\text { biperiden } 12 \mathrm{mg} / \text { day }\end{array}$ & $2 \cdot 5$ \\
\hline $\mathrm{H}-\mathrm{GN} / 33$ & SP & 8 & $\begin{array}{l}\text { Perphenazine enanthate } \\
75 \mathrm{mg} / \text { week } \\
\text { chlorpromazine } 300 \mathrm{mg} / \text { day } \\
\text { biperiden } 4 \mathrm{mg} / \text { day }\end{array}$ & 7 \\
\hline $\mathrm{UJ} / 40$ & SU & 8 & $\begin{array}{l}\text { Perphenazine enanthate } \\
150 \mathrm{mg} / 2 \mathrm{nd} \text { week } \\
\text { thioridazine } 100 \mathrm{mg} / \mathrm{day} \\
\text { biperiden } 4 \mathrm{mg} / \mathrm{day}\end{array}$ & 6 \\
\hline $\mathrm{KO} / 38$ & SH & 10 & $\begin{array}{l}\text { Chlorpromazine } 300 \mathrm{mg} / \text { day } \\
\text { flupenthixol } 2 \mathrm{mg} / \text { day } \\
\text { biperiden } 2 \mathrm{mg} / \text { day } \\
\text { nitrazepam } 5 \mathrm{mg} / \text { day }\end{array}$ & 5 \\
\hline $\mathrm{HC} / 36+$ & SP & 10 & $\begin{array}{l}\text { Cix(Z)-clopenthixol } \\
\text { decanoat } 200 \mathrm{mg} / 2 \mathrm{nd} \text { week } \\
\text { disulfiram } 200 \mathrm{mg} / \text { day } \\
\text { diazepam } 10 \mathrm{mg} / \text { day }\end{array}$ & 10 \\
\hline $\mathrm{CW} / 45$ & SP & 16 & $\begin{array}{l}\text { Perphenazine enanthate } \\
150 \mathrm{mg} / 2 \mathrm{nd} \text { week } \\
\text { chlorpromazine } 750 \mathrm{mg} / \mathrm{day} \\
\text { chloral. hydr. } 1 \mathrm{~g} / \text { day }\end{array}$ & 16 \\
\hline LS/22 & SU & 3 & $\begin{array}{l}\text { Perphenazine enanthate } \\
100 \mathrm{mg} / \text { week } \\
\text { biperiden } 6 \mathrm{mg} / \text { day }\end{array}$ & 2 \\
\hline $\mathrm{KN} / 30$ & SP & 12 & $\begin{array}{l}\text { Clozapine } 800 \mathrm{mg} / \mathrm{day} \\
\text { thioridazine } 300 \mathrm{mg} / \mathrm{day}\end{array}$ & 12 \\
\hline
\end{tabular}

*Increased alcohol consumption (no abuse)

tHospitalised for long term, prescribed disulfiram because of the risk of excessive alcohol intake when on leave. 
drogenase, fat (Sudan black B and Oil red O) and glycogen. For details cf Dubowitz and Brooke. ${ }^{15}$

The material fixed for transmission electron microscopy (TEM) was dehydrated and embedded in Epon and Vestopal epoxy resins. Semithin or ultrathin sections were cut on an ultratome (LKB 4). The semithin sections were stained in toluidin blue and examined in ordinary light microscopy or phase contrast microscopy. The thin sections were stained in $2 \%$ aqueous uranyl acetate and $2 \%$ lead citrate. The thin sections were examined in a Jeol $1200 \mathrm{EX}$ electron microscope at 60 to $80 \mathrm{kV}$.

\section{Electrophysiological investigation}

Electromyographic recordings were made from extensor digitorum brevis (EDB) motor units. Conventional bipolar needle electrodes (DISA Electronic, Skovlunde, Denmark) were used. Only recordings permitting a single test motor unit potential to be identified at voluntary contraction and at supramaximal nerve stimulation were accepted. The motor unit potentials were amplified and displayed on a Medelec oscilloscope No. 4329 and recorded on Kodak Linagraph Direct Print Paper.

The common peroneal nerve was stimulated proximally, at the fibular head, and distally, at the ankle. Stimuli were delivered through surface electrodes $0.6 \mathrm{~cm}$ in diameter. The cathode was placed over the nerve trunk and the anode $2-3 \mathrm{~cm}$ laterally or medially to the cathode. Rectangular pulse waves of $0.2 \mathrm{~ms}$ duration were used. Stimulus strength could be gradually changed from $0-100 \mathrm{~mA}$. The test motor unit potential was identified by its size and shape and all-ornone appearance. Electrical stimuli were delivered as follows:

(1) A single nerve stimulus was delivered proximally and distally. The latency difference for the test motor unit responses was calculated and the axonal conduction velocity was determined. ${ }^{16}$

(2) A single proximal and a single distal stimulus were then delivered coupled to each other. Stimulus strength was $10 \%$ above the axonal threshold at rest. The proximal stimulus was initially delayed $10-15 \mathrm{~ms}$ to permit the distally evoked, antidromic propagated nerve impulse to pass the proximal test point before stimulation. The stimulus interval was then reduced by $0.2 \mathrm{~ms}$ intervals until the second evoked motor unit potential disappeared. This was due to blocking at the proximal testing point during the refractory period after the antidromic impulse. By comparing the shortest interval without blocking with the previously determined latency difference (point 1 above) the axonal refractory period following an antidromic propagated nerve impulse was calculated. ${ }^{17}$

(3) Paired electrical stimuli were delivered proximally with stimulus intervals of $3 \mathrm{~ms}$ or less. The motor unit response interval was determined. ${ }^{18}$

Room temperature was $23^{\circ}-25^{\circ}$. Skin temperature was continuously controlled and held at $32^{\circ} \mathrm{C}$ by a DISA heater (DISA Electronic, Skovlunde, Denmark).

\section{Results}

\section{Muscle biopsy findings}

Light microscopical observations The pathological changes observed in different biopsies are displayed in tables 3 and 4 . The only changes found in the control biopsies were atrophied fibres and fibres with central nuclei. Both phenomena were observed in less than $3 \%$ of the fibres. According to Greenfield ${ }^{19}$ central nuclei in less than $3 \%$ of fibres are regarded as normal. Fibres with cross sectional areas less than $1.500 \mu \mathrm{m}^{2}$ are here looked upon as atrophic. ${ }^{2021}$

Pathological changes observed in the patient biopsies were qualitatively about the same in the two patient groups, that is, the untreated (UT) and treated

Table 3 Drugfree patients: biopsy findings

\begin{tabular}{lllll}
\hline Patients & Atrophic fibres & Central nuclei & IIC-fibres & Remarkable morphological observations \\
\hline SJ & $<1 \%$ & $<3 \%$ & $<1 \%$ & \\
LH & $<5 \%$ & $6 \%$ & $2 \%$ & \\
FH & $<5 \%$ & $8 \%$ & $20 \%$ & vacuolated and moth-eaten fibres \\
KN & $<5 \%$ & $11 \%$ & $3 \%$ & targetoid and moth-eaten fibres \\
I-ÅA & $<1 \%$ & $<\% \%$ & $<\%$ & tubular aggregates \\
PJ & $20 \%$ & $10 \%$ & irregular formazan deposits, \\
MR & $<1 \%$ & $<3 \%$ & $<1 \%$ & vacuoles and splitting \\
P-OE & $<5 \%$ & $25 \%$ & $<1 \%$ & irregular formazan deposits, \\
& & & & irreg fibres \\
& & & split and vacuolated fibres
\end{tabular}

Table 4 Patients on neuroleptics: biopsy findings

\begin{tabular}{lcccc}
\hline Patients & Atrophic fibres & Central nuclei & IIC-fibres & Remarkable morphological observations \\
\hline HM & $8 \%$ & $10 \%$ & $10 \%$ & \\
H-GN & $<5 \%$ & $<3 \%$ & $<1 \%$ & Ring-fibres and moth-eaten fibres \\
UJ & $<5 \%$ & $15 \%$ & $<1 \%$ & Ring-fibres and moth-eaten fibres \\
KO & $<5 \%$ & $8 \%$ & $<1 \%$ & Irregular formazan deposits \\
HC & $8 \% \%$ & $10 \%$ & $8 \%$ & Ring-fibres \\
CW & $<5 \%$ & $<3 \%$ & $<1 \%$ & Split fibres \\
LS & $<5 \%$ & $5 \%$ & $<1 \%$ & Vacuoles \\
KN & $30 \%$ & $40 \%$ & &
\end{tabular}


(T). There were no quantitative differences between the two groups either.

Atrophic fibres (fig 1a) were observed in most biopsies from patients and maximally in $20 \%$ (UT) or $30 \%(\mathrm{~T})$ of the fibres respectively. Central nuclei (fig 2) were also a common finding in most biopsies and maximally in $25 \%$ (UT) and $40 \%$ (T) of the fibres from a given biopsy respectively.

A number of other pathological changes were apparent in the two patient groups and at variable frequencies: When stained for oxidative enzymes the formazan granules were often irregularly distributed corresponding to changes often named "moth-eaten fibres" or "targetoid fibres", or exhibited a subsarcolemmal zone of increased staining (fig la). Ring fibres were a common finding and sometimes in an abundant amount in one and the same fascicle (Fig 1b). Myofibrillar free zones at the periphery of fibres were observed in cryostat sections (fig 3 ) but these changes were even more distinct in muscle fibres ob-
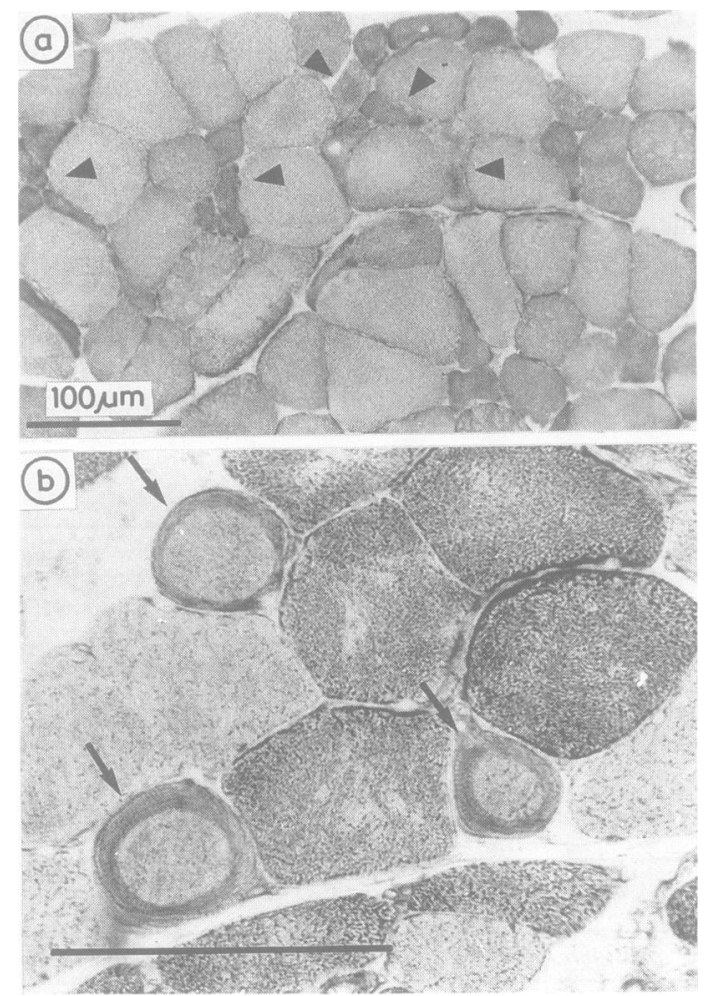

Fig 1 Cryostat cross-sections stained for NADH-TR. Bars in both sections $=100 \mu \mathrm{m}$. In (a) atrophic elongated and angulated fibres are frequent and some are indicated by arrow heads. Irrgularities in formazan deposits are observed in atrophic as well as in normal sized fibres. In (b) three ring fibres closely situated are indicated by arrows.

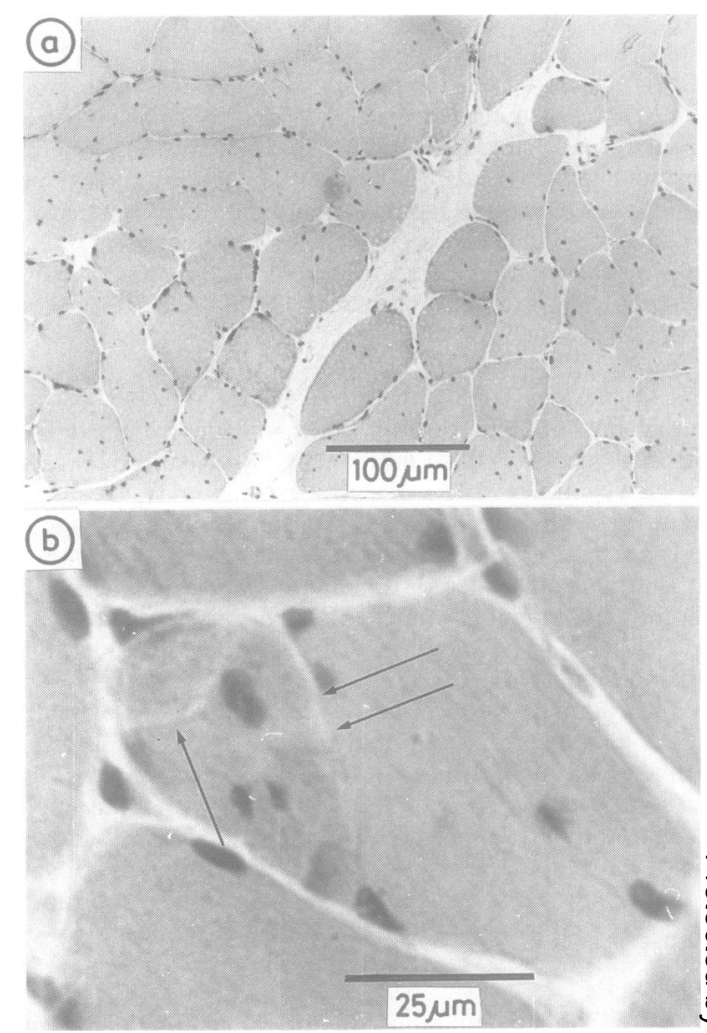

Fig 2 Cryostat cross-sections stained with haematoxylineosin, In (a) a profuse occurrence of central nuclei is demonstrated. In (b) a centrally nucleated fibre with signs of splitting is shown (arrows).

served in semithin plastic sections (Epon or Vestopal embedded, cf fig 4). Moreover in these sections widening of intermyofibrillar spaces were apparent.

Occasional fibre splitting (fig 2 b) was observed in several biopsies and often related to muscle fibre vacuoles (fig 3). The fibre type composition based on fibre stainability for acid- and alkali-stable ATPase (cf. Methods) revealed no deviations from normal, but in occasional biopsies there was an increased number of fibres with high content of both acid- and alkali-stable ATPase so called type IIC fibres. Such fibres are present in a few percent in normal extremity muscles but might increase in training situations and diseases (cf Discussion).

Changes resembling s.c. tubular aggregates were found only in one biopsy (UT).

Pathological changes besides the small number of atrophic fibres and fibres with central nuclei as described above were not observed in the biopsies from healthy volunteers. 


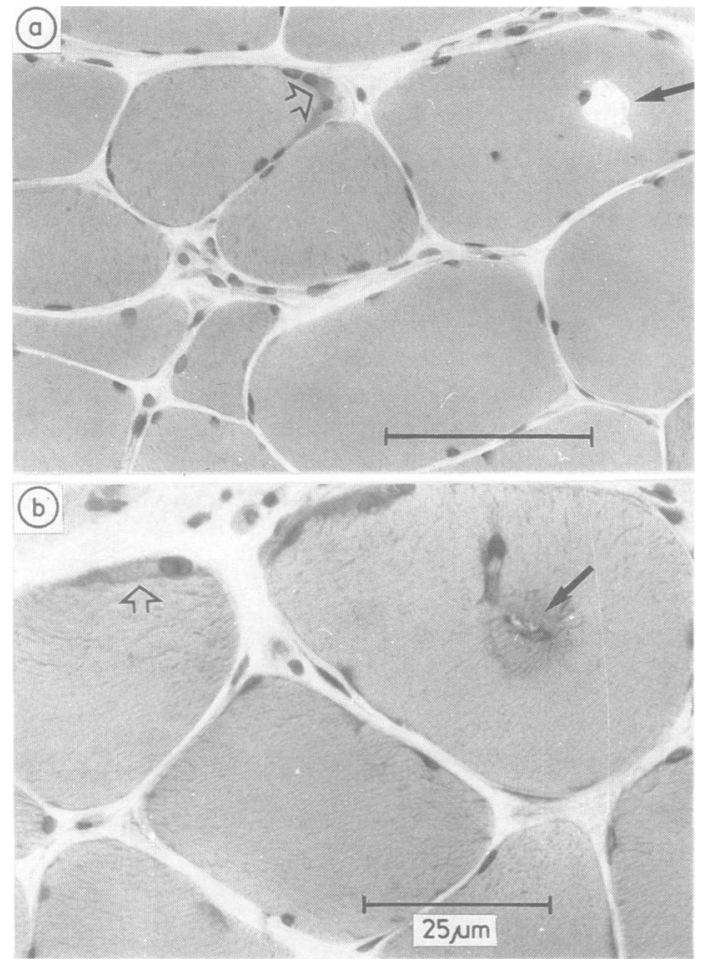

Fig 3 Cryostat cross-sections stained with haematoxylineosin. Bars in both sections $=25 \mu \mathrm{m}$. In both (a) and (b) filled arrows indicate vacuoles (in $b$ with a rimmed appearance) unfilled arrows indicate peripheral myofibrillar free zones.

Light microscopical observations on semithin plastic sections and electron microscopy of thin sections Semithin sections representing all biopsies, were investigated in the light microscope. Those areas of special interest were selected for production of ultrathin sections to be evaluated in transmission electron microscopy (TEM).

A spectrum of changes corresponding to those observed in cryostat sections were seen in the toloudin blue semithin plastic sections as well: atrophic fibres, central nuclei, ring fibres etc. Moreover it was obvious that the intermyofibrillar spaces were often increased and seemed to contain an abundance of fat droplets (fig 4).

At the ultrastructural level an abundance of glycogen was found in the widened intermyofibrillar spaces and beneath the sarcolemma (figs 5 and 6). Fat droplets were also abundant especially at the subsarcolemmal position (figs 5 and 6). Although the Z-lines were sometimes a little blurred when observed in the semithin sections (fig 4) their ultrastructure was mostly normal and the irregularities seemed mainly to be an effect of strong glycogen density close to the Z-line as observed especially on the epon embedded sections (fig 5). Z-line streaming or rod body formation as reported by Meltzer et $a l^{6}$ were not observed in this material. In some biopsies with
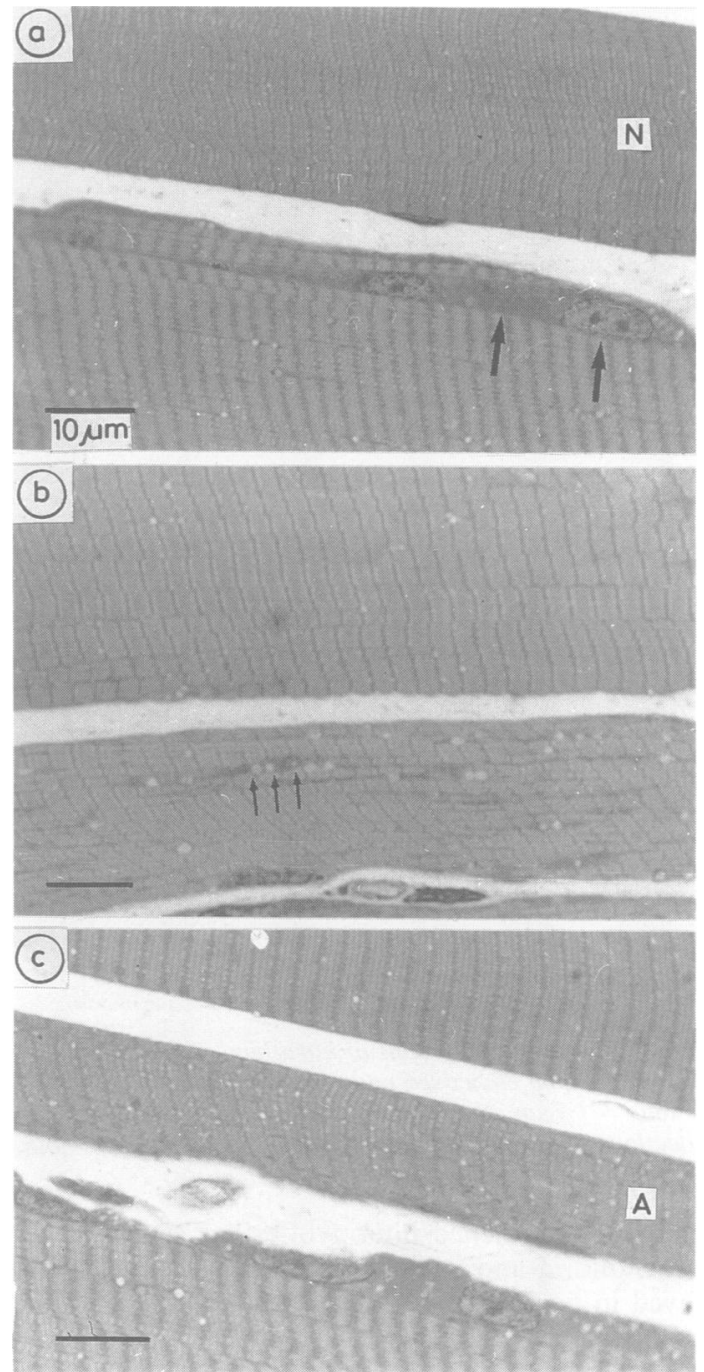

Fig 4 Semithin Epon sections stained with toluidin blue and photographed through ordinary light optics. Bars in all sections $=10 \mu \mathrm{m}$. In (a) a fibre with normal appearance is indicated with $N$. In the lower fibre striped Z-lines are observed as well as a large myofibril free zone containing two mottled nuclei with prominent nucleoli (arrows). In (b) the lower fibre exhibits widened intermyofibrillar spaces as indicated with three thin arrows. In (c) an atrophic fibre marked $A$ exhibits a high density of lipid droplets. The lower fibre in (c) has the same appearance as the lower one in $(a)$. 

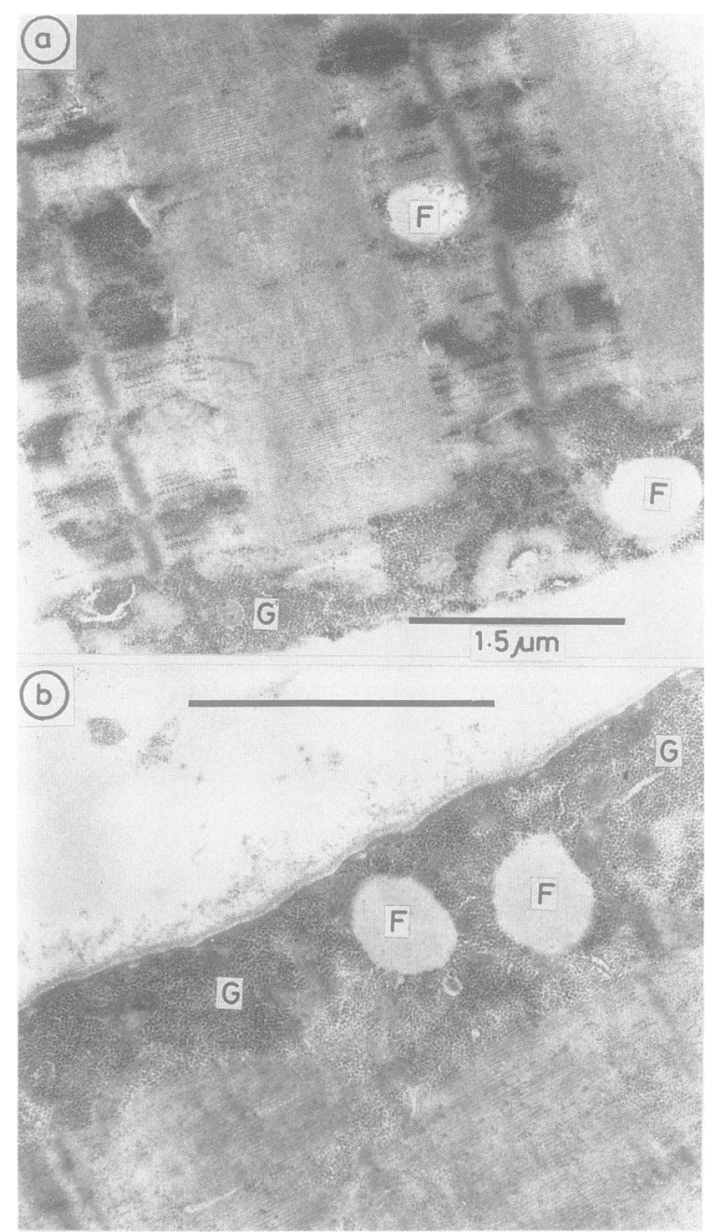

Fig 5 Electron micrographs of ultrathin longitudinal sections of Epon embedded material. Bars in both sections $=1.5 \mu \mathrm{m}$. Note fat droplets $(F)$ and abundant collections of glycogen subsarcolemmally as well as on both sides close to the Z-line.

prominently widened intermyofibrillar spaces, dense mitochondria and widened sarcotubular sacs as displayed in fig 7 were obvious in the intermyofibrillar regions.

\section{Electrophysiological findings}

Selective electromyographic recordings permitting identification of single motor unit potentials at supramaximal nerve stimulation, were difficult to obtain owing to interference with the action potentials of other motor units. However, enough selective recordings were obtained from 1-8 motor units in all but two patients belonging to the untreated patient group; in one patient it was not possible to get a selective motor unit recording and one patient refused par- ticipation in the electrophysiological investigation.

Figure 8 shows the recordings of a test motor unit potential. In (a) the potential is recorded after distal nerve stimulation and in (b) after proximal nerve stimulation. The latency difference was $9.2 \mathrm{~ms}$, which for this motor unit corresponded to a conduction velocity of $40 \mathrm{~m} / \mathrm{s}$. In (c-d) the blocking technique was used to measure the axonal refractory period. In (c), the distal stimulus was delivered $11.0 \mathrm{~ms}$ prior to the $\vec{z}$ proximal stimulus and no blocking occurred. In (d), $\overrightarrow{\vec{F}}$ the distal stimulus was delivered $10.8 \mathrm{~ms}$ prior to the $\stackrel{9}{\rightarrow}$ proximal stimulus. At this stimulus interval the nerve fibre was still refractory after the antidromic impulse 흠 when the proximal stimulus was delivered and no sec- $\frac{\bar{D}}{\vec{D}}$ ond motor unit response occurred. Thus, for this $\stackrel{\odot}{\Omega}$
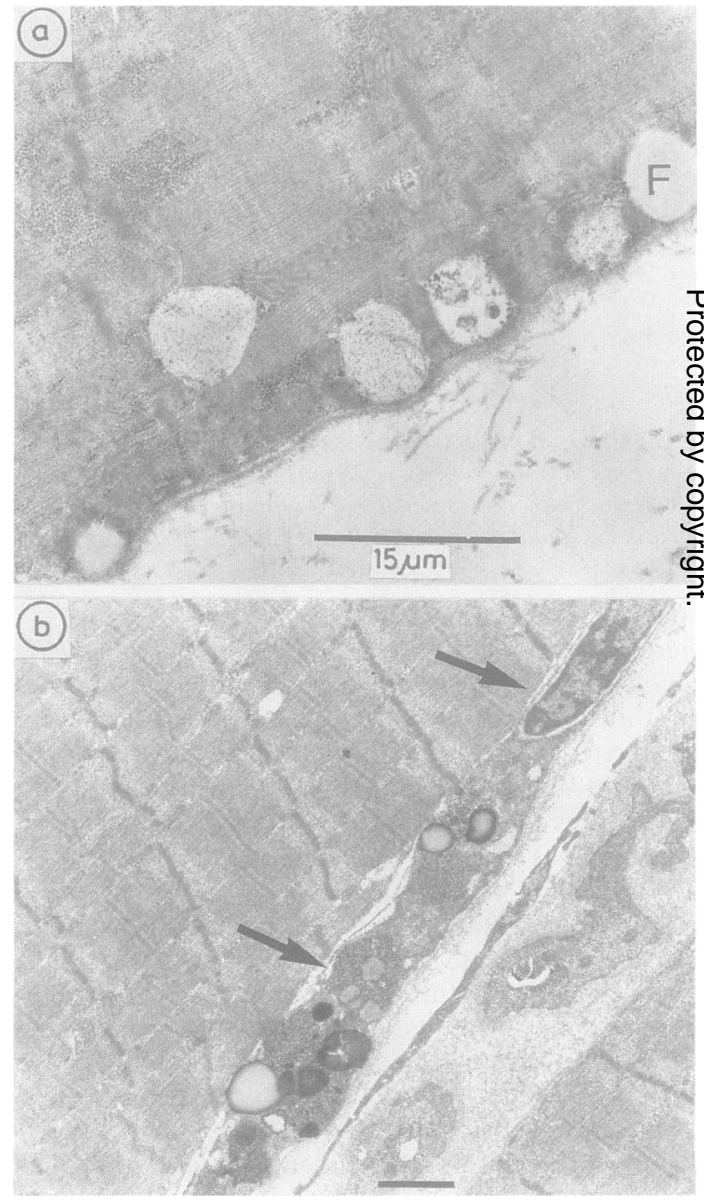

Fig 6 Electron micrographs of ultrathin longitudinal sections of Vestopal embedded material. Bars in both sections $=1.5 \mu \mathrm{m}$. In (a) there are numerous subsarcolemmal vacuoles and in (b) a satellite cell filled with glycogen and fat droplets (arrows). 


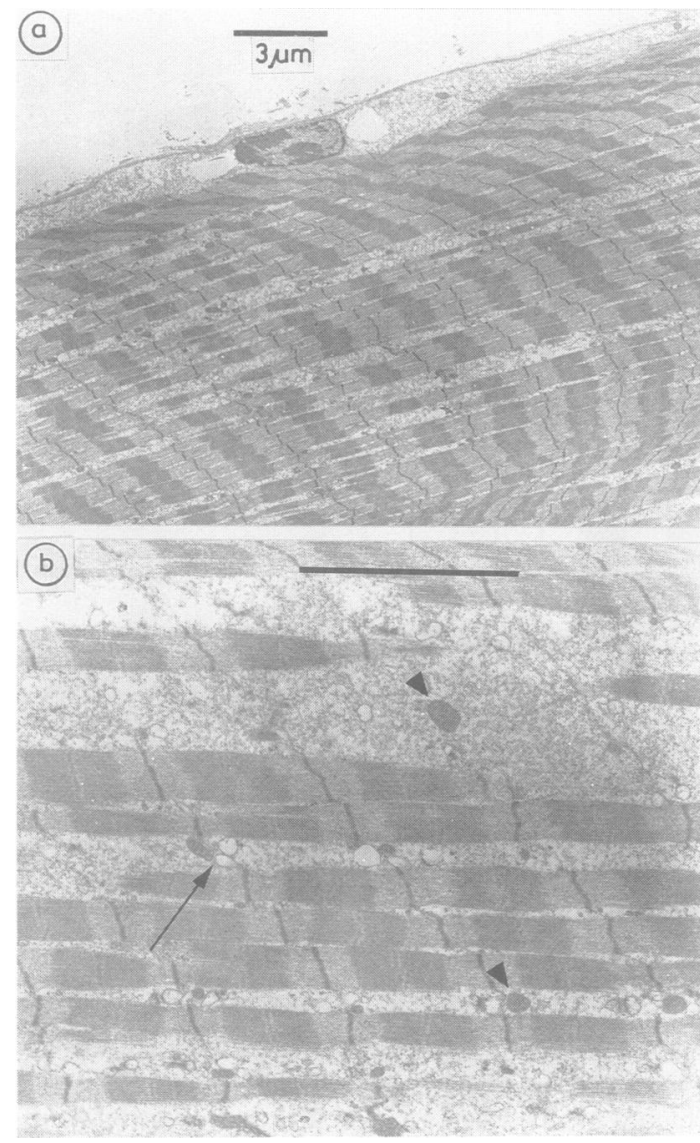

Fig 7 Electron micrographs of ultrathin longitudinal sections of Vestopal embedded material. Bars in both sections $=3 \mu \mathrm{m}$. Note the pronounced widening of intermyofibrillar spaces, which contains widened sarcotubular sacs (arrow) and small, dense mitochondria.

nerve fibre the axonal refractory period at the proximal test stimulus point was $1.8 \mathrm{~ms}(11 \cdot 0-9 \cdot 2)$.

Axonal conduction velocity Figure 9 shows the axonal conduction velocities of 25 motor units from treated patients $(T)$ and 20 motor units from untreated patients (UT) together with corresponding data from 222 motor units in healthy subjects. ${ }^{22}$ Axonal conduction velocity range was for $(\mathrm{T})$ $35-46 \mathrm{~m} / \mathrm{s}$, for (UT) $32-49 \mathrm{~m} / \mathrm{s}$, that is, within the same range as in healthy subjects $(25-54 \mathrm{~m} / \mathrm{s})$. The mean value of the axonal conduction velocities was for (T) $40.2+3.0 \mathrm{~m} / \mathrm{s}$ (M- 50) and for (UT) $38.4-4.7 \mathrm{~m} / \mathrm{s}$. These mean values were not significantly different from each other or from the corresponding mean value in healthy subjects $(39 \cdot 8-4 \cdot 9)$.
Axonal refractory period The axonal refractory periods of the motor units were for (T) motor units $1 \cdot 2-2.5 \mathrm{~ms}$, for (UT) motor units $1.5-2 \cdot 1 \mathrm{~ms}$, that is, within the same range as in healthy subjects $(1 \cdot 2-2 \cdot 8 \mathrm{~ms}) .^{23}$

Figure 10 shows the individual mean values for the axonal refractory periods and the axonal conduction velocities for each of the eight $(\mathrm{T})$ patients and the six (UT) patients together with corresponding data for 109 motor units from 22 healthy subjects. These refractory period data exhibited a mean for (T) $1.89-0.25 \mathrm{~ms}$ and for (UT) $1.80-0.06 \mathrm{~ms}$. These mean

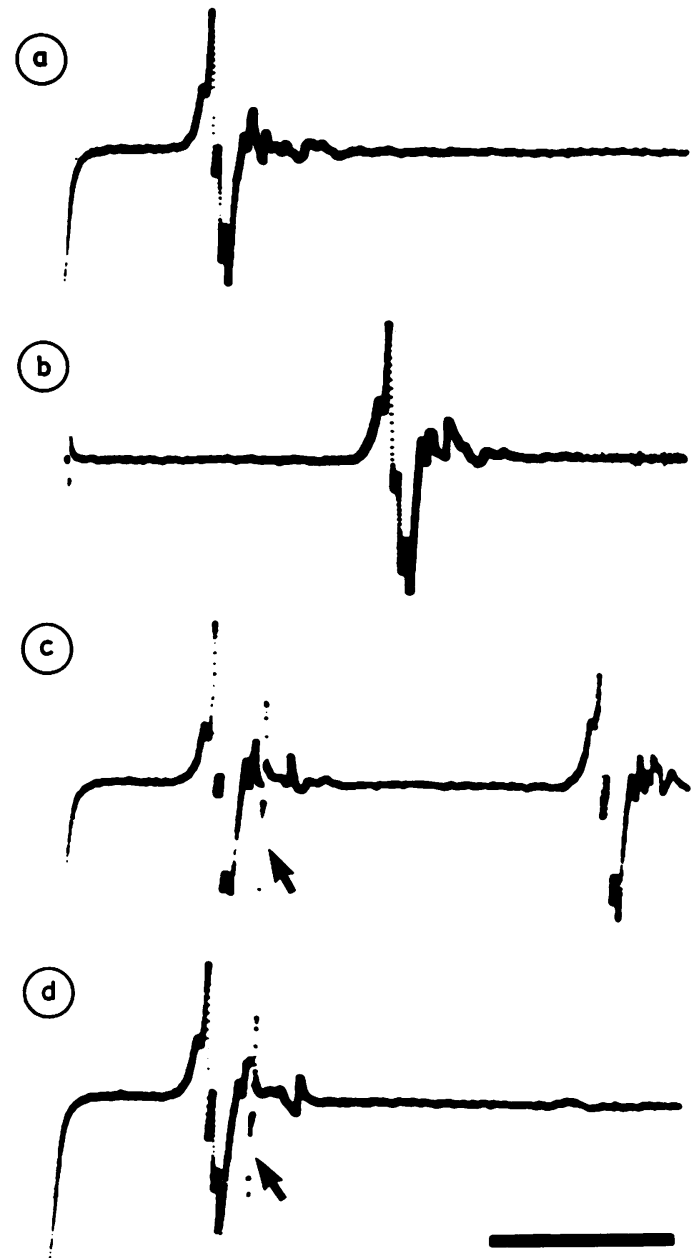

Fig 8 Electromyographic single motor unit recordings after delivering (a) a distal nerve stimulus, (b) a proximal nerve stimulus, (c) a distal and a proximal nerve stimulus coupled to each other with the proximal stimulus delayed $11.0 \mathrm{~ms}$ and $(d)$ with the proximal stimulus delayed $10 \cdot 8 \mathrm{~ms}$. Arrows indicate delayed stimulus. Time bar $=10 \mathrm{~ms}$. 


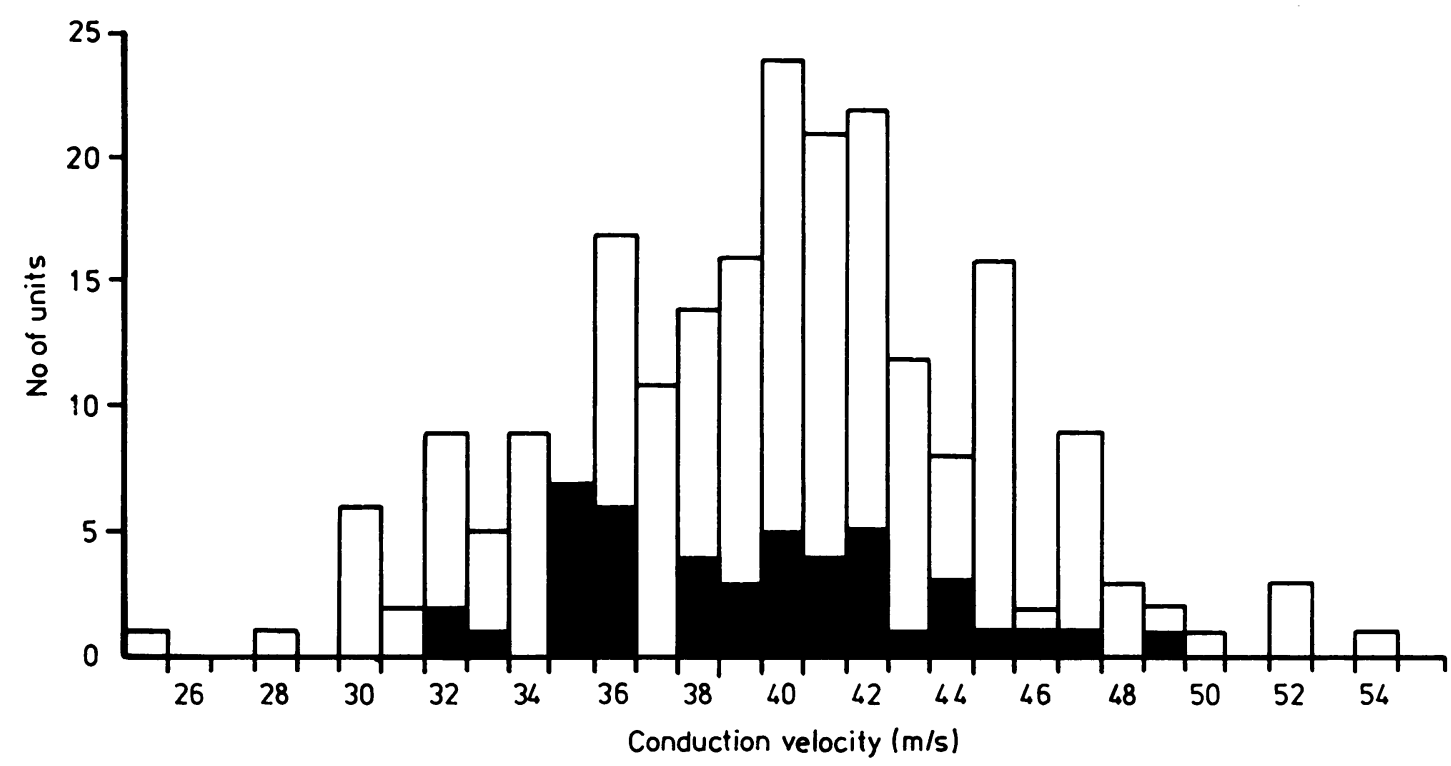

Fig 9 Axonal conduction velocity spectrum in normal subjects (white) and in schizophrenic patients (black).

values were not significantly different from each other or from the corresponding value in healthy subjects. Shortest motor units response interval When paired electrical stimuli were delivered proximally to the peroneal nerve at intervals shorter than $3 \mathrm{~ms}$, the slowing of the conduction of the second impulse propagated during the relative refractory period of the first impulse normally prevents peripheral blockings and limits the motor unit response interval to $3-5 \mathrm{~ms}^{18}$

In the schizophrenic patients $14(\mathrm{~T})$ motor units and 15 (UT) motor units paired electrical stimuli were

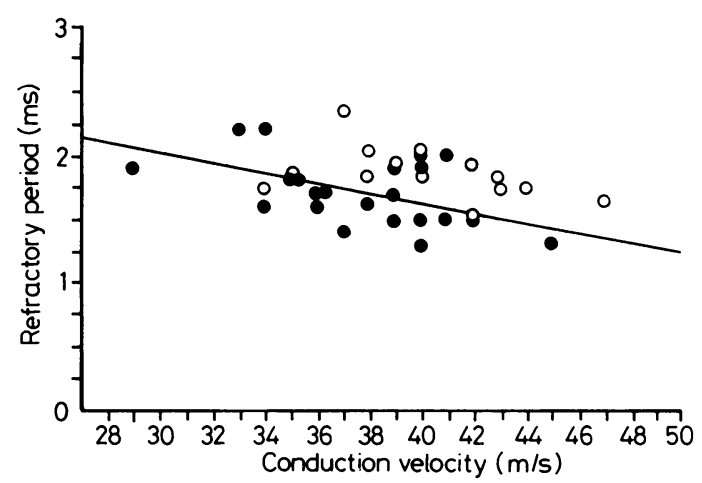

Fig 10 Axonal conduction velocity and refractory period for 22 healthy subjects (filled dots) and 14 schizophrenic patients (unfilled dots). Regression line for data from healthy subjects marked as illustration. delivered proximally to the peroneal nerve at stimuluso intervals shorter than $3 \mathrm{~ms}$. In the other motor units the potential identity was lost owing to displacement命 of the needle electrode during the experiment. For $6 / 14$ (T) motor units and for 10/15 (UT) motor units significant peripheral blockings occurred so that the second motor unit response could not be identified, which was not observed in healthy subjects. ${ }^{18}$ For the음 other motor units the response interval was within the same range as observed in healthy subjects, that is, $3-5 \mathrm{~ms}$.

\section{Discussion}

This study of two well defined groups of schizophrenic patients, neuroleptic treated and untreated, has shown significant muscle fibre morphological and electrophysiological abnormalities in both patient groups when compared with healthy subjects. It is concluded that these neuromuscular abnormalities in schizophrenics could not be attributed to neuroleptic medication or drug abuse.

The observations of atrophic fibres, central nuclei and increased number of type IIC fibres are consistent with neurogenic as well as myogenic lesions. The vacuoles, ring fibres, splitting and tubular aggregates more strongly point to a myogenic origin. However, there are no muscle biopsy findings in this study, or in previous studies of schizophrenic patients, which can not be at least occasionally found in long standing neuropathic conditions. The increased number of 
type IIC fibres should correspond to a slow type of myosin. Such fibres have been described in different neuromuscular disorders ${ }^{24} 25$ and in relation to muscular training. ${ }^{2627}$ Moore et $^{2 l^{25}}$ pointed out that such fibres were abundant in carriers of the gene for myotonic dystrophy with few symptoms and might be looked upon as early signs of neuromuscular disease.

Conventional determinations of the nerve conduction velocity of the whole nerve trunks have shown no significant difference between schizophrenic patients and healthy subjects ${ }^{928}$ and thus no signs of generalised neuropathy. This does not exclude the possibility of a selective affection of slowly conducting nerve fibres. However, the present conduction velocity data from individual nerve fibres showed the same range as observed in healthy subjects ${ }^{22}$ and thus no signs of a generalised or selective neuropathy.

While the nerve conduction velocity is most sensitive to demyelinisation the refractory period of the peripheral nerve fibre might be more sensitive to other pathological processes affecting the nerve. ${ }^{1729}$ This parameter has not been studied in psychotic disorders previously. The present single nerve fibre data were not significantly different from the observations in healthy subjects and thus revealed no signs of axonopathy.

Previous studies ${ }^{28}$ have shown a reduced number of motor units in schizophrenic patients when the technique described by McComas ${ }^{30}$ was used. Further, single fibre electromyographic studies have shown increased fibre density in schizophrenic patients and their relatives ${ }^{92831}$ and abnormal terminal nerve branching has been demonstrated morphologically ${ }^{3233}$ in schizophrenic patients. Thus, there are morphological and electrophysiological indications of denervation and reinnervation which might be due to a primary neurogenic or myogenic process. This corresponds well with the findings in the present study showing peripheral blockings when paired electrical stimuli were applied proximally to the nerve indicating impaired peripheral impulse propagation in the nerve terminal or the muscle fibres.

The present data argue against the possibility of an effect of treatment as an explanation of the present signs of neuromuscular abnormality. Neither earlier observations nor those presented here could offer a definite explanation of the observed neuromuscular changes. In a previous study significant changes of the concentrations of plasma amino acids and of central monoamine metabolites were demonstrated in schizophrenic patients and it was discussed how this might correspond to disturbed central dopaminergic transmission. ${ }^{34}$ In Parkinsonism, another disorder traditionally looked upon as a model for disturbance of the central dopaminergic system, there are clear cut structural changes in type I muscle fibres ${ }^{2135}$ which suggest some involvement of the peripheral motor system other than just secondary effects of hypokinesia and muscular hypertonus.

Possibly, disturbances of central neuron systems responsible for the schizophrenic symptoms might also be combined with peripheral motor affections explained by mechanisms related to transynaptic degeneration or multilevel defects causing major CNS symptoms and minor peripheral motor signs.

Finally it may be considered whether a generalised cell membrane defect is present in schizophrenia. Hitzemann et al $^{36}$ observed a decrease of membrane phosphatidylcholin in erythrocyte ghost preparations from schizophrenics. Hagenfeldt et al $^{37}$ observed a decreased tyrosine transport in cultured fibroblasts from schizophrenics without relation to any known amino acid transport system. They suggested a general defect of the plasma membrane function.

The study was approved by the ethical committee at The Karolinska Institute.

This study was supported by grants from the Swedish Medical Research Council (14X-04749, 12X-3875, 21P-07027) and the Vivian L Smith Foundation.

\section{References}

1 Bender L. Childhood schizophrenia: A clinical study of 100 schizophrenic children. Am J Orthopsychiatry 1947;17:40-56.

2 Cantor S, Trevenen C, Postuma R, Dueck R, Fjeldsted B. Is childhood schizophrenia a cholinergic disease? Arch Gen Psychiatry 1980;37:658-67.

3 Fish B, Alpert M. Abnormal states of consciousness and muscle tone in infants born to schizophrenic mother. Am J Psychatry 1962;119:439-45.

4 Hansoon D, Gottesman I, Heston L. Some possible childhood indicators of adult schizophrenia inferred from children of schizophrenics. Br J Psychiatry 1976;129:142.

5 Meltzer $\mathrm{H}$. Creatine kinase and aldolase in serum: abnormality common to acute psychoses. Science 1968;159:1368-70.

6 Meltzer HY. Neuromuscular dysfunction in schizophrenia. Schizophr Bull 1976;2:106-135.

7 Ikeda $\mathrm{H}$. Serum creatine phosphokinase activity in newly admitted chronic alcoholics. Folia Psychiat Neurol Japon 1977;31:9-16.

8 Meltzer HY, Crayton JW. Suberminal motor nerve abnormalities in psychotic patients. Nature 1974;249:373-5.

9 Crayton JW, Stålberg E, Hilton-Brown P. The motor unit in psychotic patients: a single fibre EMG study. $J$ Neurol Neurosurg Psychiatry 1977;40:455-63.

10 Spitzer RL, Endicott J. Schedule for Affective Disorder and Schizophrenia ( $S A D S$ ). 3rd edition. New York State Inst. Biometrics Res. New York 1977.

11 Lindholm T. The influence of uremia and electrolyte disturbance on muscle action potentials and motor nerve conduction in man. Acta Med Scand 1968;suppl.491:23.

12 Engel WK, Cunningham GC. Rapid examination of muscle tissue. An improved trichrome method for fresh-frozen biopsy sections. Neurology 1963;13:219-26.

13 Padykula HA, Herman E. The specificity of the histochemical method for adenosine triphosphatase. J Histochem Cytochem 1955;3:170-95.

14 Brooke MH, Kaiser KK. Muscle fibre types: How many and 
what kind? Arch Neurol 1970;23:369-79.

15 Dubowitz V, Brooke MH. Muscle Biopsy: A Modern Approach, London. WB Saunders 1973.

16 Borg J, Grimby L, Hannerz J. Axonal conduction velocity and voluntary discharge properties of individual short toe extensor motor units in man. J Physiol (Lond) 1978;277:143-52.

17 Borg J. Axonal refractory period of single short toe extensor motor units in man. $J$ Neurol Neurosurg Psychiatry 1980;43:917-24.

18 Borg J. Effects of prior activity on the conduction in single motor units in man. $J$ Neurol Neurosurg Psychiatry 1983;46:317-21.

19 Greenfield JG, Shy GM, Alvord EC, Berg L. An Atlas of Muscle Pathology in Neuromuscular Diseases. Edinburgh, Livingstone 1957.

20 Edström L. Differential effects on red and white muscle fibres by motility disturbance in man. Medical thesis. Stockholm 1970.

21 Edström L, Gremski W, Wroblewski R. Sulphur and phosphorus content in relation to fibre composition and atrophy of skeletal muscle in patients with Parkinsons disease. Neurol Sci 1979;41:311-23.

22 Borg J. Conduction velocity and refractory period of single motor nerve fibres in motor neuron disease. $J$ Neurol Neurosurg Psychiatry 1984;47:349-53.

23 Borg J. Refractory period of single motor nerve fibres in man. $J$ Neurol Neurosurg Psychiatry 1984;47:344-8.

24 Edström L. Histochemical and histopathological changes in skeletal muscle in late onset hereditary myopathy (Welander). J Neurol Sci 1975;26:147-57.

25 Moore GE, Roses AD, Pericak-Vance MA, Garrett Jr WE, Scahchat FH. Promiscuous expression of myosin in myotonic dystrophy. Muscle Nerve 1986;9:355-63.

26 Schantz P, Henriksson J. Increase in myofibrillar ATPase intermediate human skeletal muscle fibres in response to endurance training. Muscle Nerve 1983;6:553-6.
27 Schantz P, Billeter R, Henriksson J, Jansson E. Training induced Z increase in myofibrillar ATPase intermediate fibres in human $\mathbb{D}$ skeletal muscle. Muscle Nerve 1982;5:628-36.

28 Goode DJ, Meltzer HY, Crayton JW, Mazura TA. Physiologic $ᄋ$ abnormalities of the neuromuscular system in schizophrenia. Schizophr Bull 1977;3:121-38.

29 Kimura J. Refractory period measurement in the clinical domain. In: Waxman SC and Ritchie JM (eds), Demyelinating Disease:

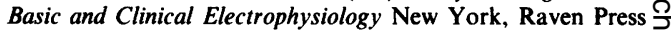
1981:239-65.

30 McComas AJ, Fawcett PRW, Campbell MJ, Sica REP. Electrophysiological estimation of the number of motor units in a human muscle. J Neurol Neurosurg Psychiatry 1971;34:121-31.

31 Peters JG. The motor unit in schizophrenic patients and their families. Biol Psychiatry 1978;13:763-7.

32 Crayton JW, Meltzer HY. Degeneration and regeneration of $\frac{C}{0}$ motor neurons in psychotic patients. Biol Psychiatry 1979; $\bar{\omega}$ 14:5:803-19.

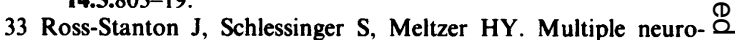
muscular abnormalities in a paranoid schizophrenic. 饮 Psychiatry Research 1980;3:53-67.

34 Bjerkenstedt L, Edman G, Hagenfeldt L, Sedvall G, Wiesel FA. $\vec{\circ}$ Plasma amino acids in relation to cerebrospinal fluid mono-amine metabolites in schizophrenic patients and healthy $\vec{\omega}$ controls. Br J Psychiatry 1985;147:276-82.

35 Edström L. Selective changes in the sizes of red and white muscle fibres in upper motor lesions and parkinsonism. J Neurol Sci 1970;11:537-50.

36 Hitzemann R, Hirschowitz J, Garver D. Membrane abnormal- O ities in the psychoses and affective disorders. J Psychiatric Res $\vec{N}$ 1984;3:319-26.

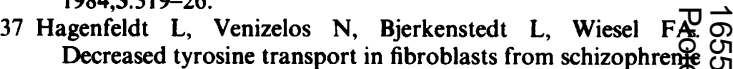
patients. Life Sciences (in press). 